\title{
ACIDENTES PROVENIENTES DO CONTATO HUMANO COM ANIMAIS MARINHOS: UMA REVISAO DE LITERATURA
}

\section{Moana Ferreira dos Santos ${ }^{1}$; Ana Paula da Conceição Fernandes de Amorim²; Ângelo Alves de Moura $^{3}$; Rafael Marques de Mesquita ${ }^{4}$}

\author{
${ }_{1}$ Bióloga. Universidade Federal do Rio de Janeiro (UFRJ). Rio de Janeiro, RJ. \\ ${ }_{2}$ Médica Veterinária. Universidade Federal do Rio de Janeiro (UFRJ). Rio de Janeiro, RJ. \\ 3 Médico Residente em Clínica Médica. Hospital da Polícia Militar de Minas Gerais (HPM). Minas \\ Gerais, MG. \\ ${ }_{4}$ Médico. Exército Brasileiro (EB). Rio de Janeiro, RJ.
}

DOI: $10.47094 /$ ICONRES.2021/17

\begin{abstract}
RESUMO
A utilização humana dos ambientes marinhos favorece situações de exposição aos riscos de acidentes provocados via contato com animais marinhos. Estes acidentes geralmente ocorrem de forma acidental, e por via ocupacional, ou durante atividades de lazer desenvolvidas nestes ecossistemas. Os acidentes de importância médica podem provocar morbidez em humanos, por meio de envenenamentos e traumas. É de extrema importância que estudos sobre estes acidentes e suas ocorrências sejam desenvolvidos, visto a modesta disponibilidade bibliográfica encontrada sobre esse tema. Diante dessa perspectiva o principal objetivo deste artigo é apresentar informações sobre o cenário recente dos acidentes oriundos do contato entre humanos e animais marinhos que apresentem relevância médica.
\end{abstract}

PALAVRAS-CHAVES: Toxinas marinhas; Animais marinhos venenosos e traumatizantes; Risco à Saúde Humana.

ÁREA TEMÁTICA: Saúde Coletiva 


\section{INTRODUÇÃO}

Os ecossistemas marinhos são atraentes à presença humana para a realização de atividades de lazer, pesca de subsistência, dentre outros diversos usos. Esta proximidade torna esses ambientes propícios a diferentes situações de exposição aos riscos de acidentes envolvendo contato humano, por via acidental ou ocupacional, com animais marinhos de relevância médica (Haddad et al., 2018; Santos et al., 2021).

Embora, os acidentes causados por animais marinhos venenosos e traumatizantes possam resultar em casos de morbidez importante em humanos, estes são minimamente investigados no Brasil (Holanda et al., 2019; Santos et al., 2021).

Os acidentes de graves consequências são passíveis de terapias geralmente sem embasamento cientifico que muitas vezes são aplicadas fora e dentro de ambientes hospitalares (Santos et al., 2017).

Tendo em vista a importância dos agravos à saúde humana oriundos destes acidentes e a pouca disponibilidade bibliográfica sobre o tema, se faz presente a necessidade de revisões como esta.

Por esta razão, o principal objetivo deste artigo é apresentar informações sobre o cenário recente dos acidentes oriundos do contato entre humanos e animais marinhos.

\section{METODOLOGIA}

Utilizou-se uma pesquisa bibliográfica para realizar este estudo transversal retrospectivo. Foram analisados artigos e trabalhos publicados nos últimos seis anos (2015 a 2021) que referem acidentes ocorridos no litoral brasileiro, com ênfase no Estado do Rio de Janeiro, RJ. Foram utilizadas bases de dados como o Portal de periódicos da Capes, PubMed, MEDLINE, SciELO, livros e artigos completos publicados em eventos acadêmicos. Os descritores utilizados foram: animais marinhos peçonhentos, toxinas marinhas, riscos à saúde humana. Os idiomas utilizados como filtros de busca foram o português e inglês. Como resultado final encontrou-se dez artigos e um livro a serem utilizados nesta revisão

\section{FUNDAMENTAÇÃO TEÓRICA}

Os acidentes resultantes do contato com animais marinhos podem ocasionar traumas e/ou estar associados a toxinas (Brusca et al., 2016; Santos et al., 2017; Santos et al., 2021). As peçonhas e os venenos são constituídos por inúmeras toxinas e podem ser encontradas em distintos grupos de animais marinhos, tais como, crustáceos, poríferos (esponjas), equinodermos (ouriços-do-mar), cnidários (águas-vivas e caravelas), moluscos e peixes ósseos (Brusca et al., 2016; Santos et al., 2021).

O aumento da presença humana nos ambientes marinhos, associado ao desequilíbrio 
ecológico nestes ecossistemas e a outros fatores resulta no aumento da exposição humana aos riscos de acidentes (Haddad et al., 2018; Santos et al., 2021).

Um estudo de 2017 evidenciou um total de ocorrências significativo no que diz respeito a acidentes provocados por animais marinhos em pescadores artesanais em atividade (Santos et al., 2021). Segundo Santos (2017), os acidentes mais frequentes com pescadores e banhistas foram os por meio de perfuração. Nestes casos envolvendo ferrões, os mais citados são os ocorridos com peixe bagre e raia ou arraia. Nestas ocorrências relataram-se sintomas como dor local persistente, mal-estar, febre e vômitos (Santos et al., 2017; Santos et al., 2021).

O estudo dos acidentes causados por animais marinhos no litoral brasileiro vem sendo negligenciado no que diz respeito ao conhecimento, controle e prevenção das doenças que envolvem esses animais. Existe uma escassez de dados epidemiológicas das ocorrências desses acidentes, o que resulta em informações ínfimas com restrições referentes à coleção de dados secundários (Reckziegel et al., 2015; Santos et al., 2021).

Sobre o ictismo (acidentes causados por peixes), Holanda (2019) considera que os acidentes provocados por arraia representam um problema de saúde negligenciado no Brasil, salientado a necessidade imediata de tratamento após a ocorrência da ferroada em seres humanos. E isto se deve ao não conhecimento da profundidade das lesões provocadas pelo ferrão, bem como as proteínas venenosas que ele emite, podendo gerar infecções secundárias.

Os bagres marinhos (família Ariidae) são os peixes ósseos brasileiros que vêm provocando o maior número de acidentes no Sudeste do Brasil (Santos et al., 2017; Santos et al., 2021).

Em relação aos acidentes ocasionados por cnidários relata-se que os mais importantes são os envolvendo as caravelas (Physalia physalis), apresentado o maior número de acidentes com gravidade em algumas regiões do litoral brasileiro (Bastos et al., 2017; Santos et al., 2018; Santos et al., 2020). Os acidentes de maior gravidade são raros, mas todas as águas-vivas podem causar alergias, o que para alguns indivíduos pode ser muito grave. $\mathrm{O}$ acidentado que se envenenar com gravidade ou desenvolver essas reações alérgicas deve buscar atendimento hospitalar imediato (Haddad et al., 2017).

\section{CONSIDERAÇÕES FINAIS}

Percebe-se que a epidemiologia desses acidentes é escassa e as informações disponíveis na literatura são mínimas e limitadas. Há uma carência de dados que especifiquem, principalmente, os animais causadores dos acidentes, e as medidas terapêuticas e preventivas adequadas.

Há falta de registros oficiais das ocorrências de acidentes causados por animais marinhos no Estado do Rio de Janeiro e desta forma não se mensura seu legítimo impacto a saúde humana.

Recomendam-se estudos que abordem essa temática, objetivando desenvolver metodologias 
específicas para a notificação, a prevenção e o tratamento desses agravos.

\section{REFERÊNCIAS}

BASTOS, D.M.R.F.; HADDAD JR, V.; NUNES, J. L. S.. Human envenomations caused by Portuguese man-of-war (Physalia physalis) in urban beaches of São Luis City, Maranhão State, Northeast Coast of Brazil. Revista da Sociedade Brasileira de Medicina Tropical, Uberaba, v. 50, n. 1, p. 130-134, Feb. 2017.

BRUSCA, RC, Moore W, Shuster SM. Invertebrates. 3rd edition Oxford University Press; 3rd edition, 2016.

HADDAD JR, V.; MORANDINI, A. C.; RODRIGUES, L. E.. Jellyfish Blooms Causing Mass Envenomations in Aquatic Marathonists: Report of Cases in S and SE Brazil (SW Atlantic Ocean). Wilderness \& Environmental Medicine. New York: Elsevier Science Inc, v. 29, n. 1, p. 142145, 2018. Disponívelem http://hdl.handle.net/11449/160167 acesso em 10 set. 2020.

HADDAD JR, V.; SZPILMAN, D.; SZPILMAN, M.. Lesões por águas-vivas - Recomendação Sobrasa. Publicado em www.sobrasa.org, Fevereiro 2017. Disponível em <http://www.sobrasa.org/ new_sobrasa/arquivos/recomendacoes/LESOES\%20POR\%20AGUAS-VIVAS_Recomendacao_ SOBRASA.pdf>. acesso em 21 out. 2020.

HOLANDA, M. N. et al . Accident and vascular injury with stingray in the Alto Juruá, Acre, Brazil: a case report. Journal of Human Growth and Development, São Paulo , v. 29, n. 3, p. 427-432, dez. 2019. RECKZIEGEL, G. C. et al. Injuries caused by aquatic animals in Brazil: an analysis of the data present in the information system for notifiable diseases. Revista da Sociedade Brasileira de Medicina Tropical, Uberaba, v. 48, n. 4, p. 460-467,Aug. 2015.

SANTOS, Moana Ferreira dos; AMORIM, Ana Paula da Conceição Fernandes de; MOURA, Ângelo Alves de; MESQUITA, Rafael Marques de. Acidentes de Interesse Médico Provenientes de Animais Marinhos: Ocorrências em Itaipu, Niterói, RJ, Brasil. SAÚDE: os desafios da pesquisa na atualidade, vol. 3, cap 43. pp 915-937. ISBN: 978-65-89069-15-7. IMEA, João Pessoa-PB, 2021.

SANTOS, Moana Ferreira dos; AMORIM, Ana Paula da Conceição Fernandes de; MOURA, Ângelo Alves de; MESQUITA, Rafael Marques de; IGREJA, Ricardo Pereira. Acidentes com Animais Marinhos Importância Médica e Socioambiental. PROFAEXt 2017. Rio de Janeiro: UFRJ, Centro de Informação Toxicológica - CIT HUCFF; 2017.

SANTOS, Moana Ferreira dos; NOUER, Simone Aranha; IGREJA, Ricardo Pereira. Águas-vivas: Acidentes de Importância Médica. In: VI InfectoRio 2018; 2018; Rio de Janeiro.

SANTOS, Moana Ferreira dos; NOUÉR, Simone Aranha; IGREJA, Ricardo Pereira. Acidentes Provenientes do Contato Humano com Águas-Vivas e Caravelas: Uma Revisão de Literatura. In: 
III Encontro Nacional de Pós-Graduação em Doenças Tropicais e Infecciosas, Faculdade de Medicina - UNESP - Botucatu, 2020. Disponível em http://www.inscricoes.fmb.unesp.br/anais_completo.asp 